\title{
Chapter 9 \\ Design Thinking as a Paradigm to Support the Ethical Revival in Higher Education
}

\author{
Geraldine Torrisi-Steele \\ https://orcid.org/0000-0002-6045-4114 \\ Griffith University, Australia
}

\begin{abstract}
The recent surge of unethical behaviour throughout all levels of higher education institutions across the world leaves little doubt of the problematic nature of ethics in higher education. The current state of ethics in universities must be seen as a call to action and must be considered a catalyst for an ethical revival in higher education leadership and administration. In the present chapter, against the background understanding of design thinking, ethics, and leadership in higher education, an argument is made for the usefulness of design thinking in moving towards the much-needed ethical revival of higher education. The fundamental premise of the present chapter is that design thinking with its emphasis on empathy is a useful paradigm for supporting the growth of an ethical mindset throughout the higher education.
\end{abstract}

\section{INTRODUCTION}

Provoked into reflection by having written the chapter in this volume entitled Ethics in higher education leadership: themes and current trends, the author mulled further over the complexities of leadership, and even more so, the complexities of ethics in higher education. Ethics according to the Cambridge dictionary have a lot to do with 'what is right and wrong'; system of accepted rules about behaviour, based on what is considered right and wrong (https://dictionary.cambridge.org/dictionary/english/ethic). The concept of ethics is grounded in social responsibility - doing right or wrong by others. It is about how our own behaviours will affect others. It seems logical then, that empathy - the ability to see something from the perspective others, could be a powerful tool for assisting the process of ethical decision making. This train of thought leads to a consideration of the usefulness of design thinking as a paradigm for

DOI: 10.4018/978-1-7998-4141-8.ch009 


\section{Design Thinking as a Paradigm to Support the Ethical Revival in Higher Education}

leadership and ethical decision making. Design thinking is a process with which the author (a teaching academic and UX designer) has familiarity with, and affinity for.

The fundamental tenet underpinning the present chapter is that design thinking has much to offer to leadership in higher education. When adopted as guiding philosophy in higher education leadership, design thinking is a valuable tool in facilitating a human-centred process for decision making and for stimulating innovative thinking in leadership and ethics. A brief review of literature reveals that others agree with the value of design thinking to leadership, and design thinking is emerging as highly desirable dimension of leadership and management.

The chapter begins with developing an understanding of design thinking. A brief discussion of the nature ethics precedes a discussion of ethics in universities, and ethics in leadership. Focus on empathy and its place in ethics and morality brings the chapter to discussion of design thinking and its usefulness in supporting the systematic change needed for ethical revival of higher education.

\section{WHAT IS DESIGN THINKING?}

To understand design thinking and its relevance to ethical decision making, it is important to first clarify the concept of design and design thinking as it is used in the present chapter. The following conceptualisation of design and design thinking is argued in a previous publication (Torrisi-Steele, in press) by the author and is paraphrased here:

Frequently, in common use, the term design is used to refer to visual appearance, aesthetics and or function of an object or to mean "to conceive and plan out in mind" or "to devise for a specific function or plan" (https://www.merriam-webster.com/dictionary/design). Design thinking is most closely related to the latter understanding of design. Design thinking is a human centred approach to problem solving. The process of design thinking connects inspiration, ideation and implementation (Brown \& Katz,2009). "Empathy, creativity and rationality to analyse and fit solutions to particular contexts" (Wrigley \& Straker, 2015 ) is at the core of design thinking. There are variations in conceptualization of design thinking. For the purposes of the present chapter, design thinking is a process for as reflexive practice, problem solving activity - a way of reasoning/making sense of things, and creation of meaning (Gasparini, 2015).

Design thinking itself is not a new concept. It has been in use for over thirty years and used to refer to the cognitive process that designers use to design objects rather than to the design of the object itself (Wrigley \& Straker, 2015). However, the term became truly established when in 1987 when Rowe published his book entitled "Design Thinking". Design thinking has, in more recent times, come into widespread use across a multitude of contexts and disciplines, and can be considered a paradigm or guiding philosophy for problem solving. Design thinking is seen as a particularly apt paradigm for the $21^{\text {st }}$ century, in which complex problems and the need for innovation dominate. Richard Buchanan (1992), calls these deeply complex problems "wicked problems". Buchanan (1992) defines wicked problems as indeterminate and therefore highly complex. Wicked problems are the 'ultimate' open-ended problem space: there is no definitive formulation, there are no 'stopping rules' or 'exhaustive list of admissible operations. There is more than one explanation of a wicked problem and every wicked problem is unique (Buchanan, 1992, p. 14). In the seminal article "Wicked problems in design thinking", Buchannan (1992) ties design thinking to wicked problems. Wicked problems are by nature ambiguous or ill-defined. As a problem solving paradigm, designing thinking is also characterized by ambiguity, meaning that there is more than one possible explanation for a phenomenon (Luka, 2014). 
Design Thinking as a Paradigm to Support the Ethical Revival in Higher Education

The process of design thinking is characterised by collaboration, constructiveness, curiosity, empathy, holism, iteration, non-judgemental ways and openness (Luka, 2014). Owen (2005, as cited in Luka 2014, p. 66) identifies other characteristics of design thinking, significantly:

- Conditional inventiveness - "what" questions are more important than "why" questions as the goal is inventing;

- Human centred focus

- Environmental-centred concern in order to guarantee sustainability

- Bias for adaptivity means applying an approach of accepting adaptive solutions fitting to the users' evolving needs wherever possible;

- Predisposition toward multi-functionality rather than mono-functional...

- Systemic vision as design thinking is holistic

- View of the generalist - for inventive creativity, contrary to the accustomed specialization, the wider the knowledge base, the more creative solution can be made

- Affinity for teamwork because multi-disciplinary teams ensure such characteristic abilities as generalization, communication across disciplines, working systematically with qualitative information and visualizing concepts.

Both a mindset and process methodology, design thinking is applicable across a wide range of disciplines and contexts (Wrigley \& Straker, 2015) to fuel creativity and innovation in the problem solving process. The design thinking as methodology is well defined and represented by Standford d. School (www.dschool.standford.edu), and is adopted by the author for the purposes of this chapter. The process of design thinking articulated by Standford d. School is as follows:

1. Empathise (achieved through observation, engagement, listening)

2. Define (analyse, unpack, make connections, and synthesise; what stood out? Ask Why? work towards insights and define the problem as a point of view statement which defines the user, expresses the need and articulates insight.)

3. Ideate

- Step beyond obvious solutions and thus increase the innovation potential of your solution set - Harness the collective perspectives and strengths of your teams

- Uncover unexpected areas of exploration

- Create fluency (volume) and flexibility (variety) in your innovation options

- Get obvious solutions out of your heads, and drive your team beyond them

4. Prototype (with the purpose of evaluating solutions, starting conversations - iterative process)

5. Test (with the aim of refining the solution, learning more about the 'user') (Plattner, n.d.)

Design thinking is a reflexive process with reflection after creation to fuel an ongoing creative process. Hence, as a methodology design thinking is iterative rather than linear. Design thinking is fundamentally abductive. Design thinking "requires one to clear one's mind of traditional solutions leading to new and creative problem solving" (Lor, 2017).

At the surface, design thinking appears not so very different than the more traditional problem solving or project methodologies in which, despite different nomenclature, the standard phases are understand or gather requirements, define, plan, prototype, implement and evaluate. What makes design thinking 


\section{Design Thinking as a Paradigm to Support the Ethical Revival in Higher Education}

distinct from other 'user-centered' approaches is 'empathy'. The foundation stone of design thinking is empathy as opposed to simply requirement or knowledge gathering. The whole design process revolves around empathy with the people who will use the 'object' of design. In fact, design thinking is much more than empathy for the people using the object of design. It is a "sharing of empathetic insights" such that all participants are immersed in the design process (Gasparini, 2015).

In the Cambridge English Dictionary online, empathy is defined as "the ability to share someone else's feelings or experiences by imagining what it would be like to be in that person's situation" (https:// dictionary.cambridge.org/dictionary/english/empathy). Empathy is about taking the perspective of others and captures both cognitive (understanding the world through someone else's perspective), emotional dimensions (feeling what others experience) (Gasparini, 2015). Hence, design thinking affords an understanding of the end user which is deeper and more holistic than the task-focused approaches of more traditional user-centred design process approaches.

Having fulfilled the empathy stage of the design thinking process, the aim of the second stage of the design thinking is defining the problem to be addressed. This is achieved through synthesis and analysis, and importantly, critical reflection, in order to eventually arrive at the creation of a point of view statement. Following the design thinking methodology as prescribed by Stanford $\mathrm{d}$ school, the point of view statement is constructed by first by making a user need statement (that usually captures some emotion) and then posing a "how might we..." question.

The problem statement identifies the gap between the current state and the desired state (i.e. the goal) of a process or product. Within the design context, a problem is understood as an unmet need. By designing a solution that meets this need, it is possible to satisfy the user.

The ideation phase which follows the problem statement is open brainstorming in which ideas are generated that align with the insights gained through empathetic exploration and the point of view statement. During this stage it is important to 'suspend all judgement' in order to generate a rich pool of ideas.

Against the above background of understanding of the nature of design thinking, ethics and the ethics of higher education leadership and administration can now be discussed.

\section{ETHICS}

According to Lillie (2001, p. 3) ethics is " the normative science of conduct, and conduct is a collective name for voluntary actions ". Despite this apparently simple definition, ethics are anything but simple. By nature, ethics are about resolving the 'right' and 'wrong' of human behaviour (Speight, 2016), but judgement of what is 'right' and what is 'wrong' is depending on a myriad of interacting factors, hence ethical decision making is quite naturally a 'messy' problem. Ethics are intertwined with values and morals, and may be defined as the "The code of values and moral principles that guides individual or group behaviour with respect to what is right or wrong " (Mihelic, Lipicnik, \& Tekavcic, 2010).

Ethics is about decision making. Ethical decision making is imprecise, and over time a number of normative ethical theories have emerged with the aim of defining criteria upon which ethical decisions should be made. Ethical theories form the basis of ethical decision making both consciously and unconsciously (Cornelius, 2002), and include deontological theory, utilitarian theory and virtue theory of ethics.

From the perspective of deontological theory, the primary concern is the motive rather than the consequences of action. According to the Deontological theory of ethics is a duty based theory whereby ethical decisions are made on the basis of what is right or wrong from the perspective of ones' duty. It 
is most often attributed to philosopher Immanuel Kant (1724-1804). Duties can be perfect or imperfect and can either require people to act in a particular way, or not act in a particular way (Cornelius, 2002). Perfect duties are never in question and hence perfect duties should always be followed. Perfect duties are a law to be followed. There can never be conflict among perfect duties (Cornelius, 2002). Imperfect duties, such as doing good for others can be argued on different grounds.

In contrast, the Utilitarian theory of ethics is consequence based and the key goal is the happiness of other people. In the utilitarian theory of ethics, what is 'good' is defined in terms of happiness and satisfaction of other people. Ethical decision making on the basis of utilitarian theory requires making decisions on the basis of which decision will generate the greatest amount good to the largest number of people (McGee, 2009). The greatest challenge in utilitarian theory is gaining a measure of the gains and losses of others (McGee, 2009).

Different from both deontological and utilitarian theories of ethics, virtue based ethics are anchored to the moral character of the person, rather than to consequences or motives. In the present time virtue ethics is gaining considerable attention. Founded on the philosophy of Aristotle, virtue ethics revolves around an individual's disposition. This disposition is developed over time rather than something with which one is born with.

"Virtuous acts are not done in a just or temperate way merely because they have a certain quality, but only if the agent also acts in a certain state, viz. (1) he knows what he is doing, (2) if he chooses it and chooses it for its own sake, and (3) if he does it from a fixed and permanent disposition" Aristotle, Nicomachean Ethics (cited in (Van Hooft, 2006, p. 7)

\section{ETHICS AND UNIVERSITIES}

According to Speight (2016, p. 12), a university is a community of students and teachers committed to the pursuit of learning, accumulation of knowledge, the transmission of this knowledge to succeeding generations, and the development of new knowledge. In addition, a university combines teaching, research, and discovery as well as community service.

As organizations, modern universities are very complicated systems. No longer simply "places of learning' or "repositories of knowledge" (Richardson \& Healy, 2019). The classic university has undergone considerable transformation as a result of massification and marketisation of higher education (Richardson $\&$ Healy, 2019). Going to university is no longer an interval in which to learn to live a more 'significant life' (Oakeshott, 2004; Collini, 2012 cited in Richardson \& Healy, 2019). The purpose of universities for students has become much more utilitarian with emphasis on employability (Richardson \& Healy, 2019). Universities now have multiplicity of purpose including "educating students to lead productive lives", "conducting research and creating new knowledge", "protecting and supporting diverse points of view", "serving as engines of opportunity and social mobility", and "defending important values" (Guthrie, 2019). Cutting across the evolving purpose of higher education is the marketisation of education, driven largely by the reduction of public funding for universities over the past 30+ years (Guthrie, 2019). In transforming, universities have grown a very large and very diverse network of stakeholders, and many different functions (Lella et al., 2012). With so many different stakeholders, and with the state of transition in which universities find themselves at present, it is not surprising that there is a rise in ethical challenges in higher education. When there are many different stakeholders and complicated social environments there is a greater likelihood that the different interests and values of the various stakeholders come into conflict, giving rise to ethical dilemmas (Mihelic, Lipicnik, \& Tekavcic, 2010). 


\section{Design Thinking as a Paradigm to Support the Ethical Revival in Higher Education}

Universities are intricate organizations and their functioning is built on trust (Speight, 2016). Trust is interwoven with ethical behaviour and is "one of the pillars of any university community" (Speight, 2016, p. 3). Building and maintaining trust in such a complex system is clearly challenging. Of the many factors which influence ethics, one of the most powerful is the personal perspectives of individuals themselves, which in turn is relative to their chosen profession and position in the university (Speight, 2016). Hence, despite the codes of ethics existing in universities in relation to research, teaching and community activity, actions often comes down to the individual perspectives, values, and beliefs (Speight, 2016). Infringement of ethical codes of conduct (or misconduct) may boil down to the management of emotions and feelings during activities such as research, leading to questionable behaviours. Unfortunately, the incidence of unethical behaviours in universities is on the increase, occurring in the various levels of universities, in research and in teaching. It seems that many, if not all, university campuses are faced with ethical challenges:

A veritable tsunami of issues have come together in recent years to challenge previously held principles on systemic integrity in Higher Education Institutions (HEIs) across much of the western world (Richardson \& Healy, 2019, p. 1).

Of the many ethical challenges, the 'big three' are plagiarism, cheating and fraud (Richardson \& Healy, 2019, p. 4).

The actions taken in institutions to deal with corruption, fraud and other breaches of integrity in higher education tend to be combative (Richardson \& Healy, 2019); finding ways of 'making it harder' to breach integrity or discouraging breaches through harsher penalties. For example, the issue of students cheating or plagiarising on assessments is a growing problem. The approach to combat the problem involves vigilance and reporting breaches, university policies around penalties for breaches, and the implementation of increasingly sophisticated software for online submission which is intended to both discourage and catch individuals 'out'. As the ethical challenges become ever more present in universities, it becomes evident that combative measures alone are insufficient. If the wave of ethical issues in universities is to recede, then what is required is a more proactive, more durable, transformative approach. That is, an approach to encourage "healthy ethical habits" and ultimately create a healthier ethical environment (Richardson \& Healy, 2019, p. 1).

There is growing evidence in literature of the recognition of the need to tackle the ethical challenges in universities on a system level and to thereby transform the present higher education culture into one more characteristically 'ethical'. For example, Gallant and Kalichman (2011, p. 27) argue that a systems approach to addressing the ethical challenges in higher education is needed because "context matters" and individual characteristics cannot be considered in isolation when seeking to understand ethical misconduct and corruption that has become systematic. Gallant and Kalichman (2011) points out the inadequacy of the usual approach where the 'ad hoc' focus is on the actions of particular individuals, and those individuals being punished:

...the research has shown that, despite two decades of a focus on educating individuals about research integrity and punishing individuals for research misconduct, the rate of research misconduct has remained virtually unchanged (p.36).

Ethical misconduct is a systemic issue, in which individuals, organizations, educational and societal factors are all significant elements (Gallant \& Kalichman, 2011). 


\section{ETHICS AND LEADERSHIP}

The pervasiveness of ethical issues in universities brings to the fore leadership in universities for two reasons: Firstly, the ethos of the institution is shaped by its leaders and their actions, and leadership is very much about setting direction and transformation. Furthermore, the ethical character of an organization is "most frequently described in terms of ethical standards of senior leaders" (Mihelic, Lipicnik, \& Tekavcic, 2010, p. 32). Secondly, in most recent times, many of the ethical issues in higher education that have attracted a great deal of public attention relate to the actions of the leaders and administrators of universities.

Leadership may be defined as "the art of persuading a follower to want to do things, activities, that the leader sets as goals" (Mihelic, Lipicnik, \& Tekavcic, 2010, p. 32). Or in other words, leadership is about influencing the perspectives and behaviour of others. For John Kotter, the leadership process involves developing a vision, aligning people with the vision, and motivating and empowering people to act. (Kotter, 1990).

Leadership like other human endeavours is very complicated. The volumes of literature surrounding leadership is testament to the complicated nature of leadership. In effort to understand and to develop frameworks for guiding leadership, three major leadership styles are identified: directive leadership, transactional, transformational leadership. Each of these is briefly described and examined in relation to ethics.

\section{Directive Leadership}

As the name suggests, directive leadership is very much task orientated. The leader initiates projects and assigns tasks and responsibilities. It is a managerial style of leadership. As described by Flamholtz (1999) directive leadership styles can be thought of as occurring along a continuum, from autocratic (where the leaders tells subordinates what to do because they are the boss and can do so) through to

- Benevolent autocratic (do it because it's the best for all concerned),

- Consultative (the leader decides but seeks input after the decision from subordinates),

- Participative (subordinates play a role in the decision making and decisions are made with agreement of all)

- $\quad$ Laissez-faire (where subordinates are able to take decision making into their own hands and do it their way; the leader being content to simply deal with their own needs).

From an ethics standpoint, directive leaders tend to make ethical decisions from their own perspective, making moral decisions on the basis of their own objectives, to varying degrees along the continuum (Aronson, 2001).

\section{Transactional Leadership}

Transactional leadership focuses on the chain of command and often works on a system of punishment and reward. Transactional leaders make it clear that rewards are dependent on performance (Hamstra, Van Yperen, Wisse, \& Sassenberg, 2014). Transactional leaders may have little interest in development of subordinates. As in directive leadership, there are varying degrees of transactional leadership: contingent 


\section{Design Thinking as a Paradigm to Support the Ethical Revival in Higher Education}

rewards (reward on basis of performance), active management-by-exception (MBE - active) (a system to prevent deviation from standards), and passive management by exception (MBE- passive) (corrective measures are applied after divergence has occurred) (Aronson, 2001). From an ethical and moral perspective, the transactional leader with high morality will provide contingent rewards with honesty and fair dealing. The moral transactional leader will likely maintain relationships with subordinates and support them to achieve the agreed goals of performance (Aronson, 2001). The ethical transactional leader will devise systems to prevent deviation from standards, but will devise them bearing in mind the opportunities for the success of subordinates - the well being of subordinates is considered (Aronson, 2001). On the side of low morality transactional leaders their concern for the well being of subordinates may be low, perhaps making it difficult for subordinates to succeed.

\section{Transformational Leadership}

Transformational leadership is on the other end of the spectrum of directive and transactional leadership. Whereas leaders of the directive and transactional leadership ilk operate on a more 'ego centric' basis, largely making decisions for their own objectives, and little or no concern for the overall development of followers, transformational leaders have focus on the development and empowerment of their followers (Aronson, 2001). Transformative leaders are charismatic and highly influential. The highly moral transformational leader leads by placing their own needs secondary to the well-being and empowerment of others. Authentic transformative leaders are virtuous, having the most desired qualities such as honesty, genuineness, generosity and performing 'good deeds' thereby exerting influence as a result of inspiration and motivation of others (Aronson, 2001). They are apparently altruistic and followers feel uplifted (Aronson, 2001).

However, not all transformational leaders are authentic and of high moral standing. Artificial transformational leaders, of low moral standing may still engage in what are charismatic and highly influential behaviours but the values driving their behaviours are polar opposite to the values of authentic transformational leaders. (Aronson, 2001) Artificial transformational leaders may do what they do for their own personal gain and power. Under the guise of developing others, they tend to foster dependence among followers. Artificial transformational leaders depend on conspiracies and distortion of truth to effectively manipulate their followers (Aronson, 2001)

From the above discussion of categories of leadership style and ethics it is obvious that whatever the leadership style, various leaders have different morals, beliefs and values upon which they act. Whatever their actions, leaders have undeniable influence and the culture of an organization is determined mostly by its leaders At institutional level, ethical violations by university leaders have negative consequences for the entire institution, usually creating "suspicion and criticism" both within and outside the institution, reducing the legitimacy and credibility, and destroying trust in higher education. Overall, the effect of ethical violations is the "undermining the reputation of universities" (Anderson, Woods, \& Walker, 2019). Those leaders with strong ethical character tend to create organization with a similar ethical character. The ethical stance of leaders tends to influence the behaviour of others within the organization (Anderson, Woods, \& Walker, 2019). If it is now also realized that many of tomorrow's leaders are educated in universities, then it also becomes clear that the ethical character of universities, will in the long term influence the ethical and moral nature of future society. From this perspective, the importance of ethical leadership in universities is self-evident. 
Ethics are completely inextricable from leadership (Gini, 2004). Which in turn implies that morality and values are inextricable from leadership. Leadership is essentially about people and relationships, and leadership is situated in a 'collective context'. Interaction with others "inherently has ethical implications" (Bawden, 2000 cited in Anderson, Woods \& Walker, 2019). Hence, it is crucial that leaders become aware of their own moral stance and their values (Anderson, Woods, \& Walker, 2019), and are then able to understand how their own morals and values (and subsequent actions) interact with the morals and values of others. They must also understand that in influencing others to follow them, leaders are creating a system of shared values between themselves and followers. Such understandings are pre-requisite to 'good' leadership (Anderson, Woods, \& Walker, 2019). Ethical leadership is an imperative.

Some works refer to ethical leadership as a separate style of leadership (Hartog, 2015). However, the view upheld in the present chapter is that all leadership must be ethical leadership, and that ethical practices are at the very core of leadership itself. There are various conceptualizations of ethical leadership. Brown, Trevino and Harrison (2005, p. 120) consider ethical leadership as "the demonstration of normatively appropriate conduct through personal actions and interpersonal relationships, and the promotion of such conduct to followers through two-way communication, reinforcement, and decision-making." However, Anderson, Woods and Walker (2019) criticize this definition on the grounds that it does not specify whose norms and does not acknowledge that some norms may actually cause harm to others.

In defining exactly what ethical leadership is, some define ethical leadership in terms of the effect of the leaders' actions on others. For the ethical leader, there should be no intention to cause harm to others and actions are grounded in motives that are 'altruistic' rather than egotistical (Anderson, Woods, \& Walker, 2019). Ethical leaders use their power in socially responsible ways, and are motivating, encouraging and empowering, enabling others to have a voice (Anderson, Woods, \& Walker, 2019). They are fair and honest in their dealings and have concern not only for individuals but for the benefit of wider society, both present and future (Hartog, 2015). Ethical leaders care for others and for society at large.

Ethical leadership has been linked to positive outcomes for individuals and for the organizations within which it is practiced. Ethical leaders develop a sense of well-being and trust in their followers and in stakeholders in wider society (Anderson, Woods, \& Walker, 2019; Hartog, 2015). Ethical leaders empower and 'bring out the best' in their followers. Their followers see their work as more meaningful and intrinsically motivating. Followers of ethical leaders are more likely to have a sense of duty and therefore more likely to work diligently (Hartog, 2015). Ethical leaders create 'safe' environments for their followers, meaning that followers are more likely to speak up without fear of repercussion. How then can ethical leadership be facilitated? It is proposed here that if leaders adopt a design thinking mindset, then it will be conducive to ethical leadership. 


\section{THE POWER OF DESIGN THINKING FOR SUPPORTING AN ETHICAL REVIVAL IN HIGHER EDUCATION}

The argument made in the present paper for the adoption of design thinking as a suitable paradigm for ethical leadership in higher education and administration is made on the following key points:

\section{Empathy, the Cornerstone of Design Thinking, Is Central to Ethical and Moral Behaviour}

The cornerstone of design thinking is empathy. As noted earlier, design thinking is a human centred paradigm and methodology for problem solving. Design thinking differs from other human centred approaches in that it extends beyond a simple identification of requirements and data gathering to taking on the perspectives of others as a pre-requisite for gaining the depth of understanding what is actually needed by the recipients of the object of design; the object being not necessarily a physical object. As articulated by Oxley, (2011) in the book entitled The Moral Dimensions of Empathy: Limits and Applications in Ethical Theory and Practice, empathy is a necessity for moral life and essential for the development of moral capabilities. "Empathy brings about awareness of another's state and makes information about the other person salient to the empathizer" (Oxley, 2011, p. 41).Empathy helps us to understand the world from the perspective of others. Empathy helps to establish an emotional connection with others.

"In the act of seeking to understand how others perceive and experience the world, empathy acts a mirror for ourselves because understanding others perceptions and experiences necessarily requires some degree of comparison between our own perceptions and experiences and that of others (Oxley, 2011). Additionally, by demonstrating to others our empathy, the feelings of others are validated. In the process, similarities often come to light and these similarities serve to "eliminate the perception of conflict between oneself and others" (Oxley, 2011, p. 6). Empathy, according to Oxley (2011), has two core epistemic functions: gathering information about the other person, and understanding the other person. Realizing the two epistemic functions of empathy requires intelligibility of the others emotions (i.e. the other person's emotions must make sense), and prima facie approval of the other's emotions. (Oxley, 2011). Empathy tends to motivate altruistic behaviours and provokes ethical behaviours (Oxley, 2011).

Empathising with the various stakeholders requires interaction with stakeholders and draws them into the problem solving space. In this way, empathy becomes a vehicle for connecting with stakeholders, and subsequently a mechanism for supporting a systems approach to problems.

\section{The Ethical Challenges in Higher Education Leadership and Administration as a Wicked Problem, and Design Thinking Is a Suitable Paradigm for Exploring the Problem Space of Wicked Problems}

Given that ethical challenges are deeply contextualised, and that the context of higher education and higher education leadership is also deeply context, and at present has no obvious solution. it is feasible to conceptualise the ethical challenges of higher education leadership and administration as belonging to the set of wicked problems. Social complexity produces wicked problems (Conklin, 2005) and the context of higher education can most certainly be characterised as socially complex. Richard Buchanan (1992), calls deeply complex problems "wicked problems". Buchanan (1992) defines wicked problems as indeterminate and therefore highly complex. Wicked problems are the 'ultimate' open-ended problem 
space: there is no definitive formulation, there are no 'stopping rules' or 'exhaustive list of admissible operations. There is more than one explanation of a wicked problem and every wicked problem is unique (Buchanan, 1992, p. 14).

Wicked problems are poorly understood and remain so until some kind of 'solution' is found (Conklin, 2005). But, there is no one definitive solution for wicked problems, the problem solving process (or at least an iteration of it) ends when a solution that is 'good enough' is arrived at. Solutions are not intrinsically right or wrong and every wicked problem is unique (Conklin, 2005). Furthermore every solution to a wicked problem is 'one-shot' meaning that it is impossible to know what the outcome of the solution is until the solution is implemented, and wicked problems have no alternative solutions there might be many potential solutions, some of which may be unthought of as yet, and judgement is required to evaluate which solutions may or may not be valid (Conklin, 2005).

In the seminal article "Wicked problems in design thinking", Buchannan (1992) ties design thinking to wicked problems and presents design thinking as a useful way of exploring the problem space of wicked problems. Not only can design thinking prove a useful tool for exploring wicked problems, but the design thinking process itself brings growing recognition of the problem as being 'wicked'. This is important since to effectively explore wicked problems it is first necessary to identify the problem as being wicked (Conklin, 2005):

"Some problems are so complex that you have to be highly intelligent and well informed just to be undecided about them" - Laurence J. Peter (cited in (Conklin, 2005, p. 1))

\section{Ethical Challenges in Higher Education Often Have No Clear-Cut Answer, Are III -Defined and Requiring Creativity and Innovative Thought}

Despite efforts to combat corruption and the erosion of ethics in higher education, the issues continue to intensify. There is a wide array of ethical challenges and an intricate network of contributing factors. Amid the complexity there is likely no single, absolute solution, only 'better solutions. Furthermore, since the context of higher education is highly dynamic and higher education is in the grip of great transformation, what is an apparent solution at one time, may or may not work in the future. The future at the present time, is highly uncertain and it cannot be assumed that established ethical thinking or tried solutions to ethical challenges will be sufficient. There is an obvious need for innovative thinking in order to move forward with creating a more ethical academy. The paradigm of design thinking invites innovation through ideation. The ideation processes of design thinking is anchored to empathetic understanding and invites collaboration and discussion. Importantly, from the perspective of design thinking, challenges are not a cause for fear or evidence of failure, rather challenges are seen in the light of opportunity to move towards the better.

\section{Design Thinking and Ethical Thinking as Critical Theory}

Ethical thinking, regardless of which theory or combination of theories are used as a framework for decision making, requires by nature critical thinking. Design thinking, through the mechanism of empathy fosters critical thinking. As an essential component of the creative and innovative process, design thinking enables the challenging of the status quo through analysis and critical thinking. The process of innovation through design thinking demands understanding of the assumptions that shape the 'solution' 
Design Thinking as a Paradigm to Support the Ethical Revival in Higher Education

and therefore provides a platform for reflective practice. The assumptions include those held by 'the designers' and the designers understandings of the assumptions of the 'user'. Assumptions include the values, virtues and morals of all the various stakeholders.

\section{Design Thinking Is Conducive to, and Integrates With, the Systems Thinking Needed for Ethical Revival in Higher Education}

Returning to empathy the corner stone of design thinking, understanding through empathy exposes multiple perspectives. In the process of design thinking, it is important not only to know what those perspectives are, but also why they exist. The 'why' is fundamental to the design thinking mindset. It is through asking 'why' that true insight is gained, the interconnected elements of the problem space become evident and encourage a systems view of the situation. As argued earlier, the revival of ethics in higher education requires change in the mindset of all stakeholders. There must be a shift from the ad hoc combatting of cases to a more systemic approach. Design thinking fuels innovation and creativity, and fosters the systems thinking needed to bring to the fore the interconnected nature of ethical behaviour. It is well acknowledged; ethical behaviours cannot be viewed merely from an individual standpoint. Peoples' values and morals are not static or innate, they evolve over time as a result of experiences and as a result of interactions with the many other components of the human social system. Furthermore, how morals and values manifest as ethical or non-ethical behaviour is heavily influenced by situational factors, and hence systems thinking approach to understanding these behaviours is clearly appropriate.

The idea that design thinking together with systems thinking is an appropriate paradigm for leadership in the present age is beginning to emerge in literature. Tate (2009 cited in (Mugadza \& Marcus, 2019 , p. 7) identifies a non-exhaustive list of systems thinking principles that are relevant to leadership in the $21^{\text {st }}$ century:

For a leader using the Systems Thinking perspective, the following aspects apply:

- views the organisation as a system and explains things in terms of the system's overall purpose

- they focus on the system's purpose ahead of its processes and procedures,

- they synthesise rather than analyse,

- they personally examine and check what's going on in the organisation,

- $\quad$ they seek to understand the system as a whole and do not let short-term pressures get in the way of this,

- $\quad$ they build and make use of feedback loops,

- they understand the complex dynamics through patterns and feedback loops rather than causeeffect links

- they value and facilitate emergence

- $\quad$ they listen to and value what the customer wants as well as understand and respond to demand

- $\quad$ they seek continuous improvement

- they encourage self-adaptation

- they consider all the players and actors of the organisation

- $\quad$ they are aware of natural oscillations

- $\quad$ they do not isolate strategy makers and strategy making from the front line

- they stimulate and seek organisational learning

- $\quad$ they embrace the edge of chaos and make the most of uncertainty (p.7) 
Leaders function within systems. The practice of leadership cannot be understood in isolation of the system within which it works. Moreover, leadership cannot be separated from ethics, since leaders will lead in ways shaped by their own morals and values. Hence a systems thinking approach to ethics in higher education leadership and administration is imperative. Quayle (2017) refers to designed leadership. Quayle's tenet is that the tools of design can be applied to leadership to create 'intentional leadership'. Leadership "designed by intent" involves articulating "core values, process values and foundation values that all interact with one another and demand reconciliation... we like the idea of intention, knowing that design is driven to move well beyond talking toward concrete action" (Quayle, 2017, p. 17).

\section{To Summarize}

Ethics is fundamentally about relationships with others and about the effect of decisions and actions on wider society. Empathy is core to a consideration and understanding of the experiences of others and subsequently, empathy is central to moral and ethical behaviours. Empathy is at the heart of design thinking. Additionally, meeting the challenges of ethics in higher education leadership is recognized as a wicked problem, requiring creativity and innovation to spawn potential solutions. Design thinking is suited to wicked problems both as a process and a paradigm. Conceivably, if a design thinking mindset is adopted by the stakeholders of higher education, in particular its leaders and administrators, it will be conducive to the creation of a more ethically sound culture throughout the whole of the higher education system.

\section{CONCLUSION}

The paradigms driving the ethical revival in higher education must necessarily align with the needs of the present time and given the inseparability of ethics and leadership, leadership itself must be fuelled by paradigms appropriate to the present. Historically, leadership has developed through the different paradigms which arise as a result of the nature of society. For example, during the industrial revolution, the classical paradigm of leadership was very mechanistic with focus on the traits of leaders. This was followed by a period of human relations and neo human relations and can be referred to as the Neoclassical paradigm during which situational leadership became popular. The contemporary paradigm from around the 1940's onwards revolves around general systems theory and thinking, with globalization and innovation as dominant ideas. The current age can be best described as a systems and design thinking innovation age (Mugadza \& Marcus, 2019).

Underpinning the present chapter is the view of the problem of ethical challenges in higher education as deeply complex, if not wicked, problems which must be urgently addressed.

Design thinking in particular, with its emphasis on empathy, is a highly desirable mindset for leaders in higher education and administration - regardless of their leadership styles. Adopting the design thinking paradigm in relation to ethical leadership brings to the fore that both leadership and ethics are about relating to people, and that empathy is a powerful tool for deeply understanding the perspectives, values and moral stances of oneself in relation to that of others. Applying the design thinking paradigm to ethics in higher education has the potential to create change so that the landscape becomes more a collective effort to work together towards the ideal of ethical standards in universities, and less of a battleground. 
Design Thinking as a Paradigm to Support the Ethical Revival in Higher Education

\section{REFERENCES}

Anderson, M., Woods, A., \& Walker, R. (2019). The linkage of ethics and leadership to world decision making process of HBCU college presidents. Academy of Educational Leadership Journal, 23(1), 1-11.

Aronson. (2001). Integrating leadership styles and ethical perspectives. Canadian Journal of Administrative Sciences, 18(4), 244-256.

Auerbach, A., \& Andrews, T. (2018). Pedagogical knowledge for active-learning instruction in large undergraduate biology courses: A large-scale qualitative investigation of instructor thinking. International Journal of Stem Education, 5(1).

Brown, M. E., Trevino, L. K., \& Harrison, D. A. (2005). Ethical leadership: A social learning perspective for construct development and testing. Organizational Behavior and Human Decision Processes, 97(2), 117-134. doi:10.1016/j.obhdp.2005.03.002

Buchanan, R. (1992). Wicked problems in design thinking. Design Issues, 8(2), 5-21. doi:10.2307/1511637

Conklin, J. (2005). Dialogue mapping: Building shared understanding of wicked problems. New York, NY: Wiley.

Cornelius, T. (2002). Application and implications of deontology, utilitarianism, and pragmatism for medical practice. In L. R. Loewy (Ed.), Changing health care systems from ethical, economic, and cross cultural perspectives (pp. 101-111). Dordrecht: Springer. doi:10.1007/0-306-46846-8_9

Flamholtz, E. G. (1990). Growing pains: How to make the transition from an entreprenuerial to professionally managed firm. San Francisco, CA: Jossey-Bass.

Gallant, T., \& Kalichman, M. (2011). Academic ethics: A systems approach to understanding misconduct and empowering change in the academy. In T. Gallant (Ed.), Creating the ethical academy a systems approach to understanding misconduct and empowering change (pp. 27-44). New York, NY: Routledge. doi:10.4324/9780203840481

Gasparini, A. (2015). Perspective and use of empathy in design thinking. In ACHI 2015: The Eighth International Conference on Advances in Computer-Human Interactions. IARIA.

Gini, A. (2004). Moral leadership and business ethics. In J. Ciulla (Ed.), The heart of leadership (pp. 25-43). Westport: Praeger Publisher.

Goodyear, P. (2015). Teaching as design. HERDSA Review of Higher Education, 2, 27-50.

Guthrie, K. (2019). Challenges to higher education's most essential purposes. New York, NY: Ithaka S+R. doi:10.18665r.311221

Hamstra, M. A., Van Yperen, N. W., Wisse, B., \& Sassenberg, K. (2014). Transformational and transactional leadership and followers' achievement goals. Journal of Business and Psychology, 29(3), 413-425. doi:10.100710869-013-9322-9

Hartog, D. (2015, April). Ethical leadership. Annual Review of Organizational Psychology and Organizational Behavior, 2(1), 409-434. doi:10.1146/annurev-orgpsych-032414-111237 
Design Thinking as a Paradigm to Support the Ethical Revival in Higher Education

Johansson-Sköldberg, U., Woodilla, J., \& Çetinkaya, M. (2013, June). Design thinking: Past, present and possible futures. Creativity and Innovation Management, 22(2), 121-146. doi:10.1111/caim.12023

Kotter, J. P. (1990). What leaders really do. Harvard Business Review, 68, 103-111. PMID:10104518

Lella, G., Fischetto, A., Cesarotti, V., Sphohrer, J., Ren, G., \& Leung, Y. (2012). Universities as complex service systems: External and internal perspectives. In Proceedings of 2012 IEEE Interantonal Conference on Service Operations and Logistics, and Informatics., (pp. 422-427). IEEE. 10.1109/SOLI.2012.6273574

Lillie, W. (2001). An introduction to ethics. New Delhi: Allied Publishers Limited.

Lor, R. (2017). Design thinking in education: A critical review of literature. IACSSM/ACEP 2017, 36-68.

Luka, I. (2014). Design thinking in pedagogy. Journal of Education Culture and Society, 2, 63-74.

McGee, R. W. (2009). Analyzing insider trading from the perspectives of utilitarian ethics and rights theory. Journal of Business Ethics, 91(1), 65-82. doi:10.100710551-009-0068-2

McKilligan, S., Fila, N., Rover, D., \& Mina, M. (2017). Design thinking as a catalyst for changing teaching and learning practices in engineering. In IEEE Frontiers in Education Conference (FIE), (pp. 1-5). IEEE.

Mihelic, K., Lipicnik, B., \& Tekavcic, M. (2010). Ethical leadership. Journal of Management Information Systems, 14(5), 31-42.

Mugadza, G., \& Marcus, R. (2019). A systems thinking and design thinking approach to leadership. Expert Journal of Business and Management, 7(1), 1-10.

Oxley, J. C. (2011). The moral dimensions of empathy: Limits and applications in ethical theory and practice. New York, NY: Palgrave Macmillan Limited. doi:10.1057/9780230347809

Plattner, H. (n.d.). An introduction to design thinking process guide. Retrieved from https://dschoolold.stanford.edu/sandbox/groups/designresources/wiki/36873/attachments/74b3d/ModeGuideBOOTCAMP2010L.pdf

Quayle, M. (2017). Designed leadership. New York, NY: Columbia University Press. doi:10.7312/ quay 17312

Richardson, M., \& Healy, M. (2019). Examining the ethical environment in higher education. British Educational Research Journal, 45(6), 1089-1104. doi:10.1002/berj.3552

Speight, J. (2016). Ethics in the university. Beverly, MA: Scrivener Publishing LLC. doi:10.1002/9781119346449

Torrisi-Steele, G. (in press). Using design thinking to think about teaching practice: Facilitating the shift from teacher-centred to student-centred approaches. International Journal of Adult Education and Technology.

Van Hooft, S. (2006). Understanding virtue ethics. New York, NY: Routledge. Taylor and Francis.

Wrigley, C., \& Straker, K. (2015). Design thinking pedagogy: The educational design ladder. Innovations in Education and Teaching International, 374-385. Retrieved from https://srhe.tandfonline.com/ doi/abs/10.1080/14703297.2015.1108214\#.Xg3rK_xOk2w 


\section{KEY TERMS AND DEFINITIONS}

Design Thinking: Both a methodology and mindset for creative and innovative problem solving. As defined by Stanford school, it is problem solving approach centred around empathy as the mechanism for gaining deep understanding of the users and their context.

Empathy: Seeing the world from the perspective of another person and understanding or experiencing the emotions they have in response to the world as they see it.

Ethics: According to Lillie (2001) ethics is "the normative science of conduct, and conduct is a collective name for voluntary actions" (p. 3). The code of values and moral principles that guides individual or group behaviour with respect to what is right or wrong (Mihelic, Lipicnik, \& Tekavcic, 2010).

Leadership: Leadership may be defined as "the art of persuading a follower to want to do things, activities, that the leader sets as goals" (Mihelic, Lipicnik, \& Tekavcic, 2010, p. 32).

Morals: Guiding principles for what is right or wrong.

Values: Are personal and social beliefs about what is good and the relative importance of those beliefs. Values motivate action on the basis of belief about what is more important. 